\title{
"Thanks for the Assignment!": Digital Stories as a Form of Reflective Practice
}

\author{
LORAYNE ROBERTSON \\ University of Ontario Institute of Technology \\ JANETTE M. HUGHES \\ University of Ontario Institute of Technology \\ SHIRLEY SMITH \\ University of Ontario Institute of Technology
}

\begin{abstract}
In this article we examine pre-service teachers' digital literacy stories and postassignment reflections for evidence of transformative pedagogy. The language arts course design employs both a new literacies approach (Lankshear \& Knobel, 2006) and a multiliteracies pedagogical framework (New London Group, 1996). These frameworks are also applied to help us examine the pre-service teachers' digital stories and reflections. The data consist of approximately 150 digital stories and written student reflections collected over three years. We are encouraged by the finding that the multimedia nature of the assignment appears to help pre-service teachers construct new understandings of literacies, particularly when the digital stories are shared as part of the adult classroom experience. We conclude that digital stories hold potential to encourage pre-service teachers to think critically about how they were taught relative to the teachers they wish to become.
\end{abstract}

\section{Introduction}

In this article we describe our research with pre-service teachers in a language arts course at an education faculty in Canada. In the first section of the paper, we outline our philosophical stance and course design, including key course assignments. Next, we discuss two theoretical frameworks which have been instrumental in assisting us with both designing and deconstructing our own modeled pedagogy, defined as: "a teaching and learning relationship that creates the potential for building learning conditions leading to full and equitable social participation" (New London Group, 1996, p. 60). Third, we use these same two theoretical lenses to seek out the transformative elements of the digital stories and reflections that our pre-service teachers create in the course as they reflect on "how they were taught" relative to "how they want to teach their own students." Our research looks at both how our pre-service teachers are learning in a multiple literacies program and what they are learning (process and product). Finally, we seek evidence that they want to embrace new understandings about pedagogy---to transform teaching and learning to meet the changing needs of their future student populations.

Technology, Literacies, Pedagogy and Reflection 
Because we are preparing pre-service teachers to teach in a digital age, our language arts course uses technology for many aspects of learning and teaching. We consider that the technological skills that pre-service teachers bring to their new role as teachers are important assets. The pre-service teachers arrive each year with mixed levels of comfort and competency with technology, but are generally adept at using digital technologies in multiple out-of-school ways: for recreational use such as gaming, cell phone applications, and music or video downloads; for garnering information from the internet; for Web 2.0 digital knowledge-sharing through wikis, blogs and social networking sites; and for presentation applications such as digital photography and movie-making. We try to help them acquire a level of expertise and comfort with technology that allows all of the pre-service teachers to participate fully in learning about language arts. We agree that the significance of the technology is not about the "toys" but about how technology can be purposed or repurposed to help the pre-service teachers and their future students learn and also participate fully in society. For these reasons, using technology for learning is a key element in our course design.

A second element of our program design is a deliberate, early immersion into complexity as we ask the pre-service teachers to think about literacy in new ways. We ask them to consider new literacies and multiliteracies, rather than literacy. New literacies, according to Lankshear and Knobel (2006), may or may not include digital technology; new literacies, in what they describe in the "ontological" sense, involves examining literacy as a social practice and this may include both pre and post typographic forms of text. New literacies include both the "technical stuff" and the "ethos stuff" (p. 25). Examples of the technical aspects of new literacies might be for example: text messaging, social media, using and constructing hyperlinks, online chats, blogging, and the new interfaces that allow remixing and publishing with considerable ease. Examples of the ethos aspects of new literacies would include for example, greater emphasis on participation, collaboration, group ownership of knowledge, and the building of relationships (Lankshear \& Knobel, 2006). This collaboration could happen in either print-rich environments or what has been described by Jewitt (2008) as an "acquisitionrich environment" (p. 248).

We ask our new pre-service teachers to consider that they are not studying literacy, but they are studying literacies - the complex nature of literacy with technical, cultural and critical aspects (Green, 1988, cited in Lankshear \& Knobel, 2006. We also ask pre-service teachers to consider multiple definitions of literacies and here we would include traditional literacy (reading, writing, speaking, listening, viewing and representing) as well as critical media literacy, digital literacy, computer literacy, information literacy, and critical literacy. As they embrace the complexity of literacies, we want them to recognize that their own literacies have been socially constructed from their experience, culture and education; that certain literacies and cultures traditionally have been more recognized or privileged in the school experience; and that they, themselves, have experienced forms of privilege or disadvantage (McIntosh, 1988) in their literacy learning. This critical perspective on literacy and technology is central to the language arts course curriculum.

According to Kellner (2000), within a critical technology landscape, technologies for education are used for democracy and for social reconstruction---new literacies and new technologies offer the potential to include voices not heard in the past. He explains, 
a critical theory of technology also sees how technology can be used, and perhaps redesigned and restructured, for positive purposes such as enhancing education, democracy, overcoming the divide between haves and have nots, while enabling individuals to democratically and creatively participate in a new economy, society and culture (p. 248).

We ask the pre-service teachers to consider how new literacies can empower individuals and groups to work toward a more democratic world (Kellner \& Share, 2007). Our course elements such as lesson design, resource selection, and assessment are all addressed within this critical technology theoretical context. For example, when they design lessons, they are asked to design critical media literacy lessons; when asked to consider resources, they are asked to find resources that are more culturally relevant for the students they will teach.

Jewitt (2008) discusses how new literacies can help to redesign education across "boundaries of difference" (p. 245). She uses the concept of a modal affordance to explain how new technologies offer new potential for expressing meaning and representing it. Within a classroom environment that employs new literacies, the students' interests and experiences become a starting point. In this scenario, the traditional teacher-student relationship changes and the classroom walls become "more porous." In our language arts course design we begin with the pre-service teachers' own experiences and introduce them to the literacy experiences of their peers using new technologies and new literacies. In this way, we adapt a socio-constructivist approach to literacies (Lankshear \& Knobel, 2007).

The third element of our program design was selected to help pre-service teachers make connections between a rapidly-evolving social environment of technology and diversity, and their role as leaders of social change. As professors, we adopt and model a new literacies instructional framework: a pedagogy of multiliteracies (New London Group, 1996). Within this framework, pedagogy is seen as a relationship that promotes the learning conditions to support full participation in communities and economies. This multiliteracies theory includes four pedagogical components: situated practice, overt instruction, critical framing and transformed practice. Situated practice is the immersion of the learner in meaningful practices within a learning community. Overt instruction refers to deliberate interventions by the teacher to guide and support the learning. Critical framing helps the learner to study literacies within contexts such as experience, culture, history and politics. The fourth element, transformed practice, refers to indicators of change or transfer from what a teacher candidate has learned into a new situation or context (New London Group, 1996). The example that follows explains how this pedagogical framework underpins our instruction in the language arts course.

Our university is in the proximity of a large urban centre, so we are enriched by our pre-service teachers' diversity of backgrounds and experiences. We begin our methods class by introducing a picture book "All the Colors of the Earth" (Hamanaka, 1994) (situated practice) and we model reading aloud. We chose this particular picture book because it shows children of all races and body types as "the norm." We discuss this in class (overt instruction) asking our classes to reflect on the nature of the picture books of their own childhoods and whether or not the pictures in those books were 
representative of the general population. In opening up this conversation, we introduce the notion of race as a social construct for many of our students (critical framing). We also introduce the notion that as future teachers, they will teach differently from how they were taught.

The lesson follow-up is an online discussion of a scholarly reading on taken-forgranted white and male privilege (McIntosh, 1988), which again, for some students, becomes an introduction to hegemony (the assumption of white as neutral); we see this as both overt instruction and critical framing. The pre-service teachers are asked to spend the week discussing their views about the reading online. The result is a lively dialogue during which many pre-service teachers admit to never having considered the lack of representation of a diverse society in picture books or in literature.

Conklin (2008) theorizes on such encounters between prospective teachers who have experienced privilege and their first understanding of how society can marginalize persons who represent others in school populations. She argues that it is essential that teacher educators model critical approaches and teaching for social justice so that the teachers they are preparing can see these teaching practices. While we hope that this impact of this modeling will be reflected in the future practice of our pre-service teachers, we undertook this study to determine evidence of whether or not this pedagogical framework and the modeling were shaping the pre-service teachers' thinking about teaching and learning. The written reflections of the pre-service teachers were the key data source for evidence of changed perceptions.

Reflection is another key element of our language arts program. We concur with Freire's (1998) description of teaching as a dynamic and dialectical movement between "doing" and "reflecting on doing" where he considers a critical reflection on one's practice as "the essential moment" (p. 43). In our conceptualization of reflection, we build on Schön's (1987) concept of the reflective practitioner and Brookfield's (1995) notion of critical reflection to include an action element with reflection. Freire for example, encourages movement beyond critical reflection to a "disposition" that combines a critical consciousness with advocacy. We embrace this emergent and expanding form of reflection that blends theory and practice but includes elements of moral agency and social justice (e.g., Brown, 2006; Dantley \& Tillman, 2006; Freire, 1998). We see a linkage between the kind of reflection that prompts teachers toward advocacy and action and the transformative elements of the multiliteracies pedagogy (New London Group, 1996) because both theories position teachers as agents of change. Our research was a form of reflective practice for us. We wanted to find out how our approach to new literacies, new technologies and a multiliteracies pedagogy (New London Group, 1996) in our language arts course was informing the future pedagogy of our pre-service teachers.

\section{Research Methodology}

Just as we have approached "literacies" in the course from a sociocultural perspective (Lankshear \& Knobel, 2007), we adopt a social constructivist paradigm in our qualitative research (Glesne, 2006) in that we see that our pre-service teachers are constructing their perceptions about teaching and students. Qualitative research is more 
appropriate for the investigation of our practice because we, the instructors, are the main research instruments as we observe, ask questions and interact with the participants (Glesne, 2006). We suggest that our research may also fall into the paradigm of "insider research" as Lankshear and Knobel (2003) discuss.

The pre-service teachers attend the Bachelor of Education program for 10 months ( 2 semesters) in a one-year post-baccalaureate program leading to teacher qualifications. They complete three assignments in a semester. For their first assignment, pre-service teachers are asked to create a personal digital story using a multimodal format to show how they came to "know" literacy, asking them to revisit their past experiences with literacy in order to identify their current attitudes toward literacy learning. Specifically, we ask them to consider how their history with literacy has impacted their learning and how this may affect their teaching. The digital stories are 3-5 minutes in length and preservice teachers are encouraged to use text, sound, graphics, focus and movement using a simple beginning program such as Photo Story 3 (which is a free download from the internet). For many of the pre-service teachers, this represents an "instant immersion" in creating multimedia. They are invited but not required to share this digital story with their peers. Following the presentation of the digital stories, the pre-service teachers are asked to compose a written reflection describing their experience with the creation and viewing of the digital stories. These written reflections on the design and viewing of the digital stories became a rich data source for us. We collected the reflections from three groups of students for three successive years. The data reported here are from the written reflections of the pre-service teachers.

As a first step in our research, we each analyzed our own practice separately using New London Group's (1996) multiliteracies framework, linking elements of our course outline to the four pedagogical components they identify. In completing this analysis, we were able to determine without difficulty that we could identify the elements of situated practice, overt instruction, and critical framing in our practice as the course professors. We then identified what we would consider to be "transformative elements" or indications that our pre-service teachers were learning about new literacies or a new pedagogy in our courses and applying this learning in other contexts. Some of the "lookfors" in the data included:

1. How are the pre-service teachers responding to a full and instant immersion into a redefinition of literacy as multiple literacies?

2. Is there evidence that our pre-service teachers are seeking simplistic explanations or moving toward more complex, deeper understandings?

3. Are they questioning and changing their own previously-held assumptions?

4. Is there evidence that they intend to introduce new elements of pedagogy into their future teaching practice?

We then analyzed our students' output data using content analysis (Berg, 2004) of the three years of digital stories and reflections to identify whether or not their reflections included transformative elements. Two reviewers analyzed the data for meaning separately, coding the pre-service teachers' statements by examining phrases, sentences, paragraphs, or a series of paragraphs. At the second stage of the analysis, the reviewers met to compare and confirm data categories. At this stage, larger categories emerged as dichotomies. Finally, we examined the reflections for elements of "transformed practice"---the fourth component of the multiliteracies framework (New London Group, 
1996). In the section that follows, we organize our key findings: that pre-service teachers valued and thanked us both for the assignment and the viewing of each other's stories; that the digital stories afforded new "spaces" for expression; that there was evidence of learning of deeper concepts such as: privilege, the need for differentiation, and the importance of safe learning spaces; and that our pre-service teachers were able to articulate transformative ideas about their future classrooms.

\section{A Dual Perspective}

\section{Findings}

What emerged strongly from the pre-service teacher reflections surprised us. They appeared to gain almost as much from viewing each other's digital literacy stories as they gained from creating their digital stories. We had not anticipated the strength with which this would be present in the data. As they created their stories, the pre-service teachers thought in new ways about literacy. They also thought about using technology in new ways and they said that the digital story created a space for their expression and growth that they had not anticipated would exist for them. What they gained from viewing each other's' digital stories was a level of acceptance and understanding that they communicated to us as multiple "aha" moments where they questioned their previouslyheld assumptions about teaching and learning. A third aspect or "the teachers they want to become" aspect of their reflections became clear with an ease we also did not anticipate. Each of these three aspects of the findings is outlined in detail below.

\section{The digital story as a new and powerful space}

Both the design and viewing of the digital stories evoked emotional responses, the nature of which was not anticipated. Emotion emerged quickly in our data analysis as an element of the process that was common to most of the pre-service teachers. First of all, the assignment and the technology were seen to be intimidating; many saw that that the task of chronicling their literacy development through a digital story format was initially overwhelming to the point that they were dreading the assignment. Throughout the process of planning and creating the story and then showing it to their peers they indicated to us that they experienced multiple emotions; one described it as a "roller coaster." They were clearly not prepared for the emotional impact of portraying their own literacy journeys. Here are some typical comments from their reflections:

Starting this assignment, I was terrified. Terrified of what I would find in myself and what I really wanted to share with others. I felt vulnerable. But my greatest fear became one of my greatest accomplishments, in discovering the power of personal journey.

While I was planning my photostory, I was overwhelmed by my history and the emotions that I wanted my story to portray. My whole life I have hidden my emotions...I put so much work into making it my own, and I am proud that I shared it with the class.

The process of creating, and sharing my own digital storytelling experience brought many surprises...I wasn't prepared for the emotions that it brought 
forward. From the very beginning... it became an incredibly cathartic experience.

I was initially afraid of putting myself on display and showing my video, but after showing it, I wonder where I learned to hide parts of myself and why I did.

It is interesting that although these pre-service teachers have been completing secondary and tertiary education assignments, the "telling" of their individual literacy stories was considered to be so revealing as to cause considerable trepidation.

In contrast to their fears, the pre-service teachers most definitely saw the digital story format itself as a new creative space and a space where they could each present their stories as equals. The digital story gave them more dimensions for teaching and learning; more space for using other skills, such as art, film and photography; and more options for how to tell their stories. One explained it as voice: "Digital storytelling allows everyone to have a voice, especially for some who are more reluctant to speak in the classroom." Another teacher candidate stated in her writing that the technology was what she appreciated most about the assignment. She explained, "By allowing us to use a multimedia story, I feel that the message of each of our stories was much more powerful." Still another wrote that she saw the photo story element of the project as a kind of mask that allowed her to act more freely than she otherwise would have. Another expressed the same consideration about the "space" afforded by technology in this reflection:

As a future educator, I can see myself using digital stories in my classroom as one way of teaching language arts. I feel that it allows students various outlets for expressing their ideas, thoughts and emotions (especially if writing isn't their forte) and provides opportunities to develop other skills (such as technology).

Another teacher candidate explained in a reflection that,

A digital story gives the viewer a glimpse into the author's life. You feel there in the moment with the author, you feel what the author is saying, you can imagine and empathize with what is being said.

Another compared the digital storytelling format with pen and paper. Here are his thoughts:

Whenever I heard language arts, I automatically thought of reading and writing and that lead to thoughts of paper and books.... Now that I have told my story using technology, it is something I want to incorporate into my language art lessons as well because I have experienced how effective it is. I feel that using technology in this assignment made our stories much more personal because we got to display images of ourselves we never usually show. 
Another teacher candidate summed up the creation of her literacy photostory in this way, "I now understand why it was referred to as a rich assignment... The use of photostory left the planning and organization so open that we could tackle the project in an almost infinite number of ways."

Assumptions, acceptance and understanding privilege

"Watching the photo stories was an unforgettable experience and I believe there can be no better lesson on perspective taking."

The impact of viewing each other's 3-5 minute literacy journeys in digital story format promoted multiple, connected responses from the pre-service teachers---evidence of powerful learning about pedagogy in several key areas. The first learning was that of acceptance. One teacher candidate found her perception of other pre-service teachers was challenged when she saw their stories, and said, "I developed a new-found respect for everyone for their tribulations in their life." Another person reported that the digital stories gave him the chance to see "everyone's history and their talents and abilities." Most of the pre-service teachers credited technology with helping them understand the diverse backgrounds of their colleagues. This comment from a pre-service teacher's written reflection is fairly representative:

I loved the experience of viewing each other's digital stories in class. I thought I knew people but I was totally wrong. After viewing their digital stories it really showed me not to be judgmental and make assumptions about anyone. Each individual has a different background history: some being positive and others negative which always needs to be taken into consideration and most importantly respected. While viewing the stories as a class, I felt like I was connecting to each person as their stories were shown even though I did not speak to that person....I realized how much power digital photo stories have.

Several pre-service teachers expressed that, up to this point in time, they had never realized the challenges faced by students who learn English as their second language (ESL). Many of them wrote that the viewing of the digital stories was a key turning point in understanding this perspective and noticing the courage and persistence English language learners have demonstrated in learning in a new country. One teacher candidate wrote,

I realize I have learnt far more from viewing of each other's digital story than I did in the creation of my own story...I consider myself to be accepting of others but the process of viewing each other's stories opened my eyes to assumptions I was unaware that I made on a daily basis...I became blatantly aware of the privileges I have had throughout my life and the article we had read on "White Privilege" crowded my mind. My classmates' literacy stories taught me so much more than I could have ever imagined. Learning of the struggles through the eyes of an English as a Second Language learner was far more effective than merely reading about it.

Another teacher candidate reflected that she found that the digital stories helped her to see what she had in common with others but also a new appreciation 
of their struggles. She wrote, "I feel this assignment was a great way of helping us bond as a class, especially in an environment that can often be exclusive and competitive." Another writes:

Never have I been so greatly impacted by an assignment. Through my personal journey of recollecting all of the pieces of me, defining my unique view of literacy, I unleashed a new awakening, an appreciation for myself and others, for how uniquely beautiful we all are. Realizing that each of us comes from such different walks of life, having a story that will touch your heart and shape your opinion, was a powerful message I hold very dear in viewing my fellow classmates' digital stories: an amazing privilege.

Most of the other pre-service teachers commented that the digital stories had caused them to consider that their future students would be individuals with unique strengths and needs. Here are some representative comments from their reflections:

One powerful message that really stood out to me is that, as teachers, we must understand that students approach literacy with different backgrounds, and we should teach in a variety of ways to accommodate all the needs.

In being privileged enough to view my classmates' stories, I was astonished at all of the talent within our classroom. In embracing ourselves, I think that this is when our full potential shows. This is something I would like to foster in my future classroom.

I was able to develop literacy skills with a relative ease when so many others faced struggles they should not have to face. This is what motivates me to become a well-informed, observant and accepting language arts teacher, and the digital story assignment was one of my first steps in this process.

Another writes:

If I repeatedly challenge myself to be mindful of others and the story they carry, then it will allow me to impart that wisdom [to] my students. Although I believe myself to be open and accepting of others, I still find moments where I have made assumptions. Critical thinking is a lifelong process, but without it we fail to recognize the beauty that can be found in the unknown. If I can encourage my students to value this commitment, then I know I have succeeded as a teacher of language arts.

\section{The teacher I want to become: A new pedagogy}

Pre-service teachers commented multiple times about classroom conditions that they valued, mentioning that they valued the choice to present their literacy story in their own way. Here is one example: 
I would like to include topics that allow students to create meanings of their own rather than being told that a certain opinion is right. I want my students to be aware that Rapunzel does not have to be a Caucasian with blonde hair; that she can live in Africa with long beautiful black dreadlocks. I wish to have stories about a boy and his two dads, and stories about thriving single parents.

Many indicated that they were happy to have the choice in whether or not they showed their digital story to the entire class. This teacher candidate states this clearly:

For me the experience of creating the story was admittedly difficult at times...sharing this aspect of my life with others I don't know too well is a little unnerving. Ultimately, I found the process and the final product of my story to be thought provoking but I was glad to be given the choice of whether or not to present it to the class.

Another reflected on safety in her present classroom and in her future classroom stating:

One of the things I learned was that I should not force a student to do something they are not comfortable with. One of the things that calmed my anxiety was knowing that it was optional to share our stories. It was our decision only. I have to admit I was actually shocked when [the prof] said we did not have to present. In all my years of education, I never had that choice. It was always, "present in front of the class or fail the course." I felt really safe in the classroom and it is something I definitely want my students to feel as well.

Another expressed his appreciation that his peers would offer their digital stories saying,

We saw our classroom as a safe environment where we would be supported. I also noticed many students choosing not to share their stories but most of them changed their minds after viewing what their peers had created...we all appreciated the gifts that were given to us in these classes and felt it appropriate to reciprocate.

This teacher candidate provided a fitting final reflection:

Watching my fellow [pre-service teachers'] digital stories was an experience I will never forget. In life there are few moments which allow you to be completely vulnerable and know that you are not being judged or criticized. This assignment was one of those moments; a true blessing.

\section{Discussion}

We set out to determine how well our pre-service teachers responded to a language arts course that was anchored in a pedagogy of multiliteracies where we 
presented pedagogy as a teaching and learning relationship that builds learning conditions leading to fuller participation (New London Group, 1996). We also wanted to see how pre-service teachers would respond to a program that asked them to embrace "new" literacies---including literacy as critical and social practice. We are encouraged by what we discovered.

First of all, we discovered that pre-service teachers may need some "nudging" to use digital technologies for the purpose of representing their literacy experiences but that they will likely find that the technology is both enabling and powerful. While initially somewhat intimidated by the assignment, there was overwhelming agreement that the assignment of the digital literacy story was a powerful learning tool that allowed equal voice.

We wanted to know if pre-service teachers could resist the simplistic definitions of literacy and we found multiple instances that the pre-service teachers reached beyond simplistic explanations and looked for more complex and deeper understandings. While it is true that a few of their reflections were superficial, most of their written work and digital photostories were deeply reflective.

What we found that we were not anticipating was the strength of the learning that was advanced through the viewing of each other's' digital stories. As evidenced by their comments in this paper, their focus in the reflections after viewing was about issues of privilege, advantage, and disadvantage, and the need for a differentiated curriculum and inclusive learning resources. We speculate that some of this discussion resulted from the deliberate choice of the first read aloud book that feature multiple, representative pictures and the scholarly article on white and male privilege.

We found also that through the vehicle of the creation and viewing of the digital stories, there were numerous examples presented that show that they were questioning their previously-held assumptions, acknowledging that they had never before considered their own privilege or how superficially they had judged their peers. The viewing of each other's stories seemed to intensify and solidify this learning. Another area that emerged from the findings was the significance that the pre-service teachers' placed on reflecting on their role as a learner. They indicated their appreciation for the importance of safe learning spaces that included choice and the "right to pass."

While we saw evidence that many of them intend to introduce these same elements into their future teaching practice, it would be a worthy study to follow some of them into their future classrooms to see how these intentions play out in the context of the world beyond the teacher preparation program. We are reminded by the comments of the pre-service teachers that adults also have needs for safety and security in their learning. As anticipated, their own experiences provided rich fodder for their learning. Provided with sufficient space to express themselves in the digital format, they responded to a rich task. They remind us that the element of choice in the presentation format, in how much of themselves they would expose to scrutiny, and whether or not they would present the digital story to peers, were all-important elements for them.

It is fair to assume that virtually every teacher educator encourages pre-service teachers to examine how they were taught and compare this with their vision of the teachers that they would like to become. Our specific goal in this research was to determine whether or not we could find evidence that pre-service teachers could employ a new literacies and multiliteracies framework with a digital literacy assignment to 
challenge some previously-held assumptions about literacy and pedagogy. While we concur to some extent with Lortie's (1975) claim that teaching is an apprenticeship of observation, we do not conclude that all of the years that our pre-service teachers have spent as students necessarily work against their ability to embrace a pedagogy that is a relationship geared toward building learning conditions that promote full social participation (New London Group, 1996). Our pre-service teachers provided ample evidence that they can use their early learning experiences as steppingstones to a transformed future classroom, one with multiple literacies, a differentiated and inclusive curriculum, and a safe space for learning. Many of the students wrote and expressed their thanks for having been given this challenging assignment. One of the pre-service teachers provided a summary of the process that speaks volumes:

It is almost impossible to describe the effect of watching my classmates' digital stories. I was impacted so much by their stories and aspects of their lives...I had no idea that these stories would have such an effect on me and I am so thankful I was part of the process, one I wish to share with my future students. I feel it is a wonderful way to express feelings, create a safe environment and build empathy. These are all elements I wish to attain in my future classroom, and I now realize can be attained through digital storytelling.

\section{References}

Berg, B. L. (2004). Qualitative research methods for the social sciences (5th ed.). Boston: Pearson.

Brookfield, S. D. (1995). Becoming a critically reflective teacher. San Francisco, CA: Jossey-Bass.

Brown, K. M. (2006). Leadership for social justice and equity: Evaluating a transformative framework and andragogy. Educational Administration Quarterly, 42(5), 700-745.

Conklin, H. G. (2008). Modeling compassion in critical, justice-oriented teacher education. Harvard Educational Review, 78(4), 652-674.

Dantley, M. E., \& Tillman, L. C. (2006). Social justice and moral transformative leadership. In C. Marshall \& M. Oliva (Eds.) Leadership for Social Justice: Making Revolutions in Education (pp.16-30). Boston, MA: Pearson/Allyn and Bacon.

Freire, P. (1998). Pedagogy of freedom: Ethics, democracy, and civic courage. Lanham, MD: Rowman \& Littlefield.

Glesne, C. (2006). Becoming qualitative researchers: An introduction (3rd ed.). New York, NY: Pearson.

Hamanaka, S. (1994). All the colors of the earth. New York, NY: HarperCollins.

Jewitt, C. (2008). Multimodality and literacy in school classrooms. Review of Research in Education, 32(1), 241-267.

Kellner, D. (2000). New technologies/new literacies: Reconstructing education for the new millennium. Teaching Education, 11(3), 245-265. 
Kellner, D., \& Share, J. (2007). Critical media literacy, democracy and the reconstruction of education. In D. Macedo \& S. Steinberg (Eds.), Media literacy: A reader (pp.323). New York, NY: Peter Lang.

Lankshear, C., \& Knobel, M. (Eds.). (2003). New literacies: Changing knowledge and classroom learning. Buckingham, UK: Open University Press.

Lankshear, C., \& Knobel, M. (2006). New literacies: Everyday practices and classroom learning. Maidenhead, Berkshire, UK: Open University Press.

Lankshear, C., \& Knobel, M. (2007). Sampling "the New" in new literacies. In M. Knobel, \& C. Lankshear (Eds.) A new literacies sampler (pp.1-24). New York, NY: Peter Lang.

Lortie, D. C. (1975). Schoolteacher: A sociological study. Chicago, IL: University of Chicago Press.

McIntosh, P. (1988). White privilege: Unpacking the invisible Knapsack. Retrieved November, 30, 2011, from http://www.amptoons.com/blog/files/mcintosh.html New London Group. (1996). A pedagogy of multiliteracies: Designing social futures. Harvard Educational Review, 66(1), 60-92.

Schön, D. (1987). Educating the reflective practitioner: Toward a new design for teaching and learning in the professions. San Francisco, CA: Jossey-Bass.

Author Biographies

Lorayne Robertson is Assistant Professor and Graduate Program Director in the Faculty of Education at the University of Ontario Institute of Technology. Her research interests include digital literacy, critical literacy and media literacy.

Janette Hughes is Associate Professor in the Faculty of Education at the University of Ontario Institute of Technology. Her research focuses on digital literacies, new literacies and multimodal text creation. Her current research explores social justice issues through digital literacies.

Shirley Smith is the Academic Advisor and a member of the Teaching Faculty in the Faculty of Education at the University of Ontario Institute of Technology. Her research interests focus on integrating digital technology into teacher education programs. 